\title{
An Assessment of Practice of Conflict Management in Ethiopian Higher Institution: The Case of Madda Walabu University
}

\author{
Abdeta Mamo Hiko \\ College of Social Science and Humanities, Department of Civics and Ethical Studies, \\ Madda Walabu University, Ethiopia
}

\begin{abstract}
The assessment of practice of Conflict Management Practice in Madda Walabu University is the concern of this research article. Conflict is the situation in which one party perceives that its interests are being opposed or negatively affected by another party which is in the same group, in another group, in the same organization or in another organization The major problems which initiate this research are: the prevalence of conflict between several parties in the University, problem on perception of conflict and of the conflict management system of the institution. The major objectives of the research are: Assessing the conflict resolution practice of Madda walabu University, assessing the major sources of conflict in the organization, assessing the attitudes that an employees of the organization have towards conflict and forwarding possible solutions for the problems identified from the collected and analyzed data. The major limitations faced in conducting this research are: Some respondents did not give the required full information because of the fear that they have on this area and insufficiency of time that is provided to conduct this research. Both primary and secondary sources of information are used in collecting the data. Questionnaires are distributed to the institution's academic, non-academic and administrative staff members and the information gathered is analyzed accordingly. According to the analysis made, there is a wide range of conflict in the organization, a problem of conflict perception is also observed but, there is no special training and orientation prepared to change this perception. The conflict management practice of the organization is found to be poor. There is also a tendency to relate the effectiveness in conflict management to gender difference. To avoid the above problems; the organization should prepare several occasions in which the employees can develop the relationship between them, a special training and orientation program should be prepared in order to create better grasping on conflict related issues. Additionally, several points are forwarded as a recommendation to solve the problem observed.
\end{abstract}

Keywords: Conflict Assessment, Conflict Management, Madda Walabu University

DOI: $10.7176 /$ RHSS/11-5-01

Publication date:March $31^{\text {st }} 2021$

\section{Introduction}

Conflict is being taken as an inevitable aspect of modern life. For any organizations to perform effectively, interdependent individuals and groups must establish working relationships across organizational boundaries, between individuals and among groups.

Individuals or groups may depend on one another for information, assistance or coordinated action. Such interdependence may foster cooperation or conflict. As people with different backgrounds, points of view, values, needs and personalities interact; a variety of conflicts often develop. This situation holds true specifically in higher educational institutions because of the fact that most of the people have different backgrounds and personalities. There are several factors that contribute for the existence of conflict. These factors are broadly classified in to three: communication factors, structural factors and personal behavior factors.

Having said about aspects of conflict let as briefly see what a conflict actually is? There are large numbers of definition which is given by several scholars on the area. But the most common comprehensive definition that we all can agree up on is: conflict is the situation in which one party perceives that its interests are being opposed or negatively affected by another party which is in the same group, in another group, in the same organization or in another organization. Accordingly, we can classify those conflicts in to: intragroup conflict, intergroup conflict, intra-organizational conflict and inter-organizational conflict. There is also other type of conflict which there is also other type of conflict which happens within one self and between peoples who came from different cultures, which are called intrapersonal conflict and cross cultural conflict respectively.

Conflicts are either functional or dysfunctional. Functional conflict is a confrontation between groups that enhances and benefits the organization's performance. Those conflicts which refer to a confrontation or interaction between groups that harm the organization or hinder the achievement of organizational goals are dysfunctional conflicts. To this end, the managers of the organization are supposed to avoid those dysfunctional and motivate the functional ones. Recent ideas on conflict recognize that conflict is neither inherently good nor bad but can be either depending on how it is dealt with. Rather than eliminating conflict this view stresses that what is important is that conflict should be effectively managed. So managers are required to acquire effective know how on how to solve the conflicts encountered by the organization. 
In order to solve dysfunctional conflicts existed in an organization; there are conflict management tools to be applied. These tools are commonly called "conflict management styles" which incorporates; avoiding, collaborating, accommodating, competing and compromising. In addition to these, negotiations and third party's interventions are also used as potential means of resolving conflict.

\subsection{Problem statement}

The fact that individuals have different backgrounds, point of views, values, needs, personalities and other additional realities prevailing in an organizational environment made an organization a battle in which conflict is common. Regardless of the quality of manager's leadership or his or her style of management and regardless of how well planned the organizational structure is, conflicts will occasionally arise within an organization. In fact every organization undergoes a certain amount of internal conflict that must be recognized and dealt with in a positive fashion if the organization is to prosper. In neither case, if the organization is tends to recognize all the conflicts encountered in a negative way, it will most likely lose some of the benefits that it can obtain. It may be said that it is the mismanagement of conflict rather than conflict itself that causes real trouble in an organization. Management's task is to recognize conflict whenever it occurs and use it whenever possible to secure the organization's best advantage.

With this regard, Madda Walabu University encountered several conflicts since its existence which are existed between different parties in the institution. As far as the institution's conflict history is concerned, several individuals who were its employees were resigned from it because of the conflict that they confronted with different parties in the organization. Currently also, there are several dysfunctional conflicts which are observed between several parties in the organization. For instance frequent conflicts are being observed between academic staff members of the institution and campus deans. There is also a conflict which is often observed between the academic staff members with the rest of the institution's administrative staffs like personnel and finance department heads. The nonacademic staff members of the organization are also faced several conflicts in between themselves and with administrative and academic staff members of the organization because of existence of several sources of conflict and a wide range of conflict of interest between these parties. Because of this fact, employees of an organization are being less committed to their responsibilities, there is also an increasing rate of turnover, there is low level of worker's job satisfaction ...etc. this in turn creates some gap in quality service provision and the overall effectiveness of the organization,

On the other hand, there is a tendency to recognize all conflicts encountered in an organization as a destructive conflict. There is also failure to apply an appropriate style or mechanism of conflict management to solve the conflicts. These problems made conflict management an issue at Madda Walabu University. To this end, the institution called for any interested researcher who is willing to conduct a research on several organizational issues including the one under which this research is conducted eight months ago All these realities provoke this research to assess the conflict and conflict management practice of Madda walabu University so that some useful recommendations will be forwarded.

\subsection{Objective of the study}

The general objective of this study is the assessment of practice of the conflict management in Ethiopian Higher Education the case of Madda Walabu University and the Specific objectives are; Assessing the major sources of conflict in the organization, Assessing the attitudes that an employees of the organization have towards , Identifying the types of conflict which are commonly existed in the University and Evaluating the outcomes of the conflicts confronted by the organization.

\subsection{Research Methodology}

Data sources In order to get all the necessary information on the area under which the research is conducted, both the primary and secondary sources of information are used. Several Books, Magazines, Newspapers. Journals, articles, Internet sources and materials which are prepared by an organization like organizational manuals, broachers---etc. were used to collect necessary information from secondary sources. Information from primary source was collected by using questionnaire. In order to make the sample representative, the researcher applied a combination of random, convenience and stratified sampling methods. Hundred (100) questionnaires were prepared. Thirty five (35) questionnaires were distributed to all of the administrative staffs (including the top leadership of the University. Twenty four (24) questionnaires were distributed to the non-academic (supportive) staff members of the institution randomly and the rest forty one (41) questionnaires were distributed to the academic staff members of the institution using stratified sampling technique which bases the department to which they are belongs to. 


\section{Literature Review}

\subsection{Definition and nature of conflict}

Several scholars provided a wide range of definitions for the term conflict and they are also provided several natures of conflict that are supposed to be taken in to consideration while dealing with it. The following few paragraphs present some of definitions and natures of conflict given by the scholars. There has been no shortage of definitions of conflict. But despite the divergent meanings the term has acquired, several common themes underlie most definitions. Conflict must be perceived by the parties to it; whether or not conflict exists is a perception issue. If no one is aware of a conflict, then it is generally agreed no conflict exists. Additional commonalities in the definitions are opposition or incompatibility and some form of interaction. These factors set the conditions that determine the beginning point of the conflict process.

We can define conflict, then, as a process that begins when one party perceives that another party has negatively affected, or is about to negatively affect, something the first party cares about[1].

Conflict is a process in which one party perceives that its interests are being opposed or negatively affected by another party [2]. A conflict may be defined as the pursuit by two different persons of goals that are incompatible so that gains by one person must inevitably come about at the expense of the other [3].

The term conflict has been used at times to describe the antecedent conditions to the conflict episode (for example, scarcity of resources), affective states of individuals such as hostility or anxiety, cognitive states of individuals relative to their awareness of conflict situations and conflict behavior states ranging from passive resistance to overt aggression. So conflict refers to all types of opposition or antagonistic interaction[5].Conflict is when two or more values, perspectives and opinions are contradictory in nature and haven't been aligned or agreed about yet[6] In political terms, "conflict" refers to an ongoing state of hostility between two or more groups of people. Conflict as taught for graduate and professional work in conflict resolution commonly has the definition: "when two or more parties, with perceived incompatible goals, seek to undermine each other's goalseeking capability" [7].

\subsection{Views of conflict}

It is entirely appropriate to say there has been "Conflict" over the role of conflict in groups and organizations. One school of thought has argued that conflict must be avoided, that it indicates a malfunctioning within the group. We call this the traditional view. Another school of thought, the human relations view, argues that conflict is a natural and inevitable outcome in any group and that it need not be evil, but rather has the potential to be a positive force in determining group performance. The third, and most recent, perspective proposes that conflict can be a positive force in a group but explicitly argues that some conflict is absolutely necessary for a group to perform effectively. We label this third school the interactions approach. Let's take a closer look at each of these views.

2.2.1 The Traditional view

The early approach to conflict assumed all conflict was bad. Conflict was viewed negatively, and it was used synonymously with such terms as violence, destruction, and irrationality to reinforce its negative connotation. Conflict, by definition, was harmful and was to be avoided. The traditional view was consistent with the attitudes that prevailed about group behavior in the 1930s and 1940s. Conflict was seen as a dysfunctional outcome resulting from poor communication, a lack of openness and trust between people, and the failure of managers to be responsive to the needs and aspirations of their employees.

The view that all conflict is bad certainly offers a simple approach to looking at the behavior of people who create conflict. Since all conflict is to be avoided, we need merely direct out attention to the causes of conflict and correct these malfunctioning in order to improve group and organizational performance. Although research studies now provide strong evidence to dispute that this approach to conflict reduction results in high group performance, many of us still evaluate conflict situations utilizing this outmoded standard..

2.2.2 The Human Relations View

The human relations position argued that conflict was a natural occurrence in all groups and organizations. Since conflict was inevitable, the inhuman relations school advocated acceptance of conflict. They rationalized its existence: It cannot be eliminated, and there are even times when conflict may benefit a group's performance. The human relations view dominated conflict theory from the late 1940s through the mid-1970s.

2.2.3 The Interactions View

While the human relations approach accepted conflict, the interactions approach encourages conflict on the grounds that a harmonious, peaceful, tranquil, and cooperative group is prone to becoming static, apathetic, and no responsive to needs for change and innovation. The major contribution of the interactions approach, therefore, is encouraging group leaders to maintain an ongoing minimum level of conflict-enough to keep the group viable, self-critical, and creative. Given the interactions view, it becomes evident that to say conflict is all good or bad is inappropriate and naïve. Whether a conflict is good or bad depends on the type of conflict. Specifically, it's necessary to differentiate between functional and dysfunctional conflict [8]. 


\subsection{The conflict process}

When we describe an incident involving conflict, we are usually referring to the observable part of conflict-the angry words, shouting matches, and actions that symbolize opposition. But this manifest conflict is only a small part of the conflict process. As Exhibit 1 below illustrates, the conflict process begins with the sources of conflict like; Incompatible goals, different values, and other conditions lead one or both parties to perceive that conflict exists. We will look closely at these sources of conflict later because understanding and changing the root causes is the key to effective conflict management.

\subsubsection{Sources of conflict in organizations}

Incompatible Goals A common source of conflict is goal incompatibility. Goal incompatibility occurs when one employee's or departments personal or work goals seem to interfere with another person's or department's goals. Differentiation:-differences in personal values, attitudes, perceptions, cultures, educational back ground, and other related factors may result in conflict

Task interdependence:-Conflict tends to increase with the level of task interdependence. Task interdependence exists when team members must share common inputs to their individual tasks, need to interact in the process of executing their work, or receive outcomes (such as rewards) that are determined partly by the performance of other. The higher the level of task interdependence, the greater the risk of conflict, because there is a greater chance that each side will disrupt or interfere with the other side's goals.

i. Pooled interdependence- This is the weakest form of interdependence (other than independence), in which work units operate independently except for reliance on a common resource or authority.

ii. Sequential interdependence- This occurs when the output of one person or unit is becomes the direct input for another person or unit.

iii. Reciprocal interdependence- This is the highest level of interdependence, in which work output is exchanged back and forth among individuals or work units. For example, bus drivers are dependent on the maintenance crews to keep the buses in good repair, and the maintenance crews are dependent on the drivers to operate the vehicles wisely so that their work is minimized.

Scarce Resources:-Scarce resources generate conflict because scarcity motivates people to compete with other who also need those resources to achieve their objectives.

Ambiguous Rules:- Ambiguous riles-or the complete lack of rules-breed conflict, because uncertainty increases the risk that one party intends to interfere with the other party's goals. Ambiguity also encourages political tactics, and in some cases, employees enter a free-for-all battle to win decisions in their favor. This explains why conflict is more common during mergers and acquisitions. Employees from both companies have conflicting practices and values, and few rules have developed to minimize the maneuvering for power and resources. On the other hand, when clear rules exist, employees know what to expect from each other and have agreed to abide by those rules.

Communication problems:-Conflict often occurs as a result of the lack of opportunity, ability, or motivation to communicate effectively. Let's look at each of these causes. First, when two parties lack the opportunity to communicate, they tend to explain past behaviors and anticipate future actions. Unfortunately, stereotypes are sufficiently subjective that emotions can negatively distort the meaning of an opponent's actions, there by escalating perceptions of conflict. Moreover, without direct interaction, the two

sides have less psychological empathy for each other. Second, some people lack the necessary skills to communicate in a diplomatic, non-confrontational manner. When one party communicates its disagreement in an arrogant way, opponents are more likely to heighten their perception of the conflict. Arrogant behavior also sends a message that one side intends to be competitive rather than cooperative. This attitude may lead the other party to reciprocate with a similar conflict management style. Consequently, as we explained earlier, ineffective communication often leads to an escalation in the conflict cycle.

Ineffective communication can also lead to a third problem: less motivation to communicate in the future. For example, an accountant was verbally abused by an information services manager soon after he was hired. Since then, he has avoided the manager, leaving some problems undetected and unresolved. Another employee reported that the relationship with his manager deteriorated to such an extent that for five months they communicated only by e-mail. These reactions aren't surprising. Socio emotional conflict is uncomfortable, so people are less motivated to interact with others in a conflicting relationship.

Unfortunately, less communication can further escalate the conflict because there is less opportunity to empathize with the opponent's situation and opponents are more likely to rely on distorted stereotypes of the other party. In fact, conflict tends to further distort these stereotypes through the process of social identity we begin to see competitors less favorably so that our self-identity remains strong during these uncertain times.

The lack of motivation to communicate also explains (along with different values and beliefs, described earlier) why conflict is more common in cross-cultural relationships. People tend to feel uncomfortable or awkward interacting with co-workers from different cultures, so they are less motivated to engage in dialogue with them. With limited communication, people rely more on stereotypes to fill in missing information. They 
also tend to misunderstand each other's verbal and nonverbal signals, further escalating the conflict. 2.3.2 Manifest Conflict

Conflict perceptions and emotions usually manifest themselves in the decisions and overt behaviors of one party toward the other. These conflict episodes may range from subtle nonverbal behaviors to warlike aggression. Conflict is also manifested by the style each side uses to resolve the conflict, such as whether one side tries to defeat the other or find a mutually beneficial solution. These styles influence each side's decisions and behaviors. Consequently, they play a critical role in determining whether the conflict will escalate or be resolved quickly.

2.3.3 Conflict Escalation cycle

The conflict process in Exhibit above shows arrows looping back forum manifest conflict to conflict perceptions and emotions. These loops represent the fact that the conflict process is really a series of episodes that potentially come together into an escalation cycle or spiral. It doesn't take much to start this conflict cycle-just an inappropriate comment, a misunderstanding, or undiplomatic action. These behaviors communicate to the other party in a way that creates a perception of conflict. Even if the first party did not intend to demonstrate conflict, the second party's response may create that perception. If the conflict remains task-related, both parties may resolve the conflict through logical analysis. However, the communication process has enough ambiguity that a wrong look or word may trigger an emotional response by the other side and set the stage for socio emotional conflict. These distorted beliefs and emotions reduce each side's motivation to communicate, making it more difficult for them to discover common ground and ultimately resolve the conflict. The parties then rely more on stereotypes and emotions to reinforce their perceptions of the other party. Some structural conditions increase the likelihood of conflict escalation. Employees who are more confrontational and less diplomatic also tend to escalate conflict.

\subsubsection{Conflict outcomes}

It's not surprising that people normally associate conflict management with reducing or removing conflict. However, task related conflict should be encouraged under some conditions. Conflict management isn't necessarily about minimizing conflict. It refers to interventions that alter the level and form of conflict in ways that maximize its benefits and minimize its dysfunctional consequences. This sometimes means increasing the level of task-related conflict, which helps people recognize problems, identify a variety of solutions, and better understand the relevant issues. This positive conflict encourages people to consider new perspectives and debate these emerging views.

Conflict is also beneficial where intergroup conflict improves team dynamics within those units. Teams increase their cohesiveness and task orientation when they face an external threat. Conditions of moderate conflict motivate team members to work more efficiently toward their goals, thereby increasing the team's productivity [9]

Functional vs Dysfunctional Conflict out comes

Generally, conflict out comes can be classified in to functional and dysfunctional. These can be discussed over the next few paragraphs: Modern views on conflict recognize that there are both negative and positive consequences of conflict. Some conflicts support the goals of the group and improve its performance; these are functional, constructive forms of conflict. Additionally, there are conflicts that hinder group performance; these are dysfunctional or destructive forms of conflict. Of course, it is one thing to argue that conflict can be valuable for the group, and another to be able to tell if a conflict is functional or dysfunctional. The demarcation between functional and dysfunctional is neither clear nor precise. No one level of conflict can be adopted as acceptable or unacceptable under all conditions. The type and level of conflict that creates healthy and positive involvement toward one group's goals today may, in another group or in the same group at another time, be highly dysfunctional.

The criterion that differentiates functional from dysfunctional conflict is group performance. Since groups exist to attain a goal or goals, it is the impact the conflict has on the group, rather than on any individual member, that determines functionality. Of course, the impact of conflict on the individual and its impact on the group are rarely mutually exclusive, so the ways that individuals perceive a conflict may have important influence of its effect on the group [ibid 9]. However, this need not be the case, and when it is not, our focus will be on the group. So whether an individual group member perceives a given conflict as being personally disturbing or positive is irrelevant. For example, a group member may perceive an action as dysfunctional, in that the outcome is personally dissatisfying to him or her. However, for our analysis, that action would be functional if it furthers the objectives of the group [10].

\subsection{Types of conflict}

There are different types of conflict based on the parties involved in it. The following classification is the commonly accepted ones.

2.4.1 Intrapersonal conflict

At one time or another, every employee experiences conflict within himself or herself. A person may have 
conflicting goals. He or she may lack the required ability for a particular job. His or her path may be blocked by other people, lack of facilities, rules and regulations, etc. Regardless of the source, these conflicts can cause a person frustrations, tension and anxiety. There is in fact no such thing as "the perfect job" there is no job which provides total satisfaction. All jobs entail some degree of stress and in fact, some tension may be considered desirable. However, if the tension, anxiety and frustration are too great, serious personal harm may follow.

Basic Types of Intrapersonal Conflict

Four basic types of conflict that may take place within a person are as follows:

1. Approach-Approach Conflict $(++)$

2. Approach-Avoidance Conflict (+-)

3. Avoidance-Avoidance Conflict (- -)

4. Double Approach-Avoidance Conflict (+ -+ -)

Approach-Approach Conflict:- Here a person is faced with the problem of choosing from two equally powerful positive goals. He or she would like to have both but must choose only one. This limitation of choice causes internal conflict which leads to frustrated behavior. A young lady has two young men who both want to marry? A woman has two jobs open to her, both equally attractive. Which should she choose?

Approach-avoidance conflict:-. This refers to a goal which has some strong positive features and some strong negative features. On the one hand, a person would like to move towards the goal but on the other hand he or she would like to stay away from it. An employee is offered a promotion in another department. The job is very interesting but there is a lousy boss". What should he or she do? Avoidance- Avoidance Conflict:- In this situation, there are two alternatives to choose from but both are negative. A worker has to choose between two boring jobs. A manager has to reach the office before 9 A.M. for an important meeting. He is already late. If he takes the highway he is likely to be held up in the rush hour traffic. If he takes the city route, he will have so many traffic lights to cross; he may still not make it on time. What should he do?

Double approach - avoidance conflict:- this refers to a situation in which the individual is faced with two goals to choose from, both of which have some negative and some positive features. A high performer might find he or she in this "double bind" if management, being impressed by his performance, offers him two higher level positions have some discouraging features even though they pay higher salaries. What he or she do? Here a person is faced with the problem of choosing from two equally powerful positive goals.

2.4.2 Interpersonal conflict

The second basic type of conflict that we consider in this chapter is that which occurs between one individual and another or between an individual and the group to which he or she belongs, or between different groups within an organization. Most employees are concerned about their position, status, power, etc., within the organization and resent any encroachment of them. Also, they are often competing with each other for recognition, approve al, and promotion. Quite often, interpersonal conflicts are also interdepartmental for example, between a manager of one department and a manager of another, or between one department and another. Many people find interpersonal conflict stimulating and challenging. But not all do, particularly the losers.

Sometimes, to promote his or her own interests, or through foolishness, an individual will break the norms of the group to which he or she belongs. For example, a person may work too hard, ignore a strike call, or informal on a colleague. This will invite hostility and retaliation from the rest of the group. And so another type of interpersonal conflict comes into existence [11].

2.4.3. Intergroup conflict

Intergroup conflict exists when one group attempts to achieve its goals at the expense of the goal attainment of another group in the organization. Thus, conflict is the opposite of the desired cooperation and coordination between groups in an organization. Unfortunately, it is all too common. To complete the definition of conflict, managers need to recognize that intergroup conflict is a cyclical process involving four repeated steps: frustration, conceptualization, behavior, and outcome [11 ibid].

2.4.4 Intragroup conflict

Is a type of conflict which is created between parties within a given group? This type of conflict happen because of various reasons pertaining to personal, group or organization as a whole

2.4.5 Intra-organizational conflict

This is a type of conflict which happens between several parties within an organization. It is not uncommon to see several parties and departments which fight over limited resources, conduct an interdependent work, communicate several times over the works for which they are responsible together...etc. All these can be sited as potential sources of this type of conflict. It can be inter group conflict or intragroup conflict.

2.4.6 Inter-organizational conflict

Several organizations encountered conflicts between themselves because of different reasons. This type of conflict is called inter-organizational conflict. 


\subsubsection{Cross cultural conflict}

Doing business with people from different cultures is commonplace in our global company where cross- border mergers, joint ventures, and alliances are the order of the day. Because of differing assumptions about how to think and act, the potential for cross cultural conflict is both immediate and huge. Success and failure, when conducting business across cultures, often hinges on avoiding and minimizing actual or perceived conflict. Awareness of the cross cultural differences (individualism/collectivism, perceptions of time, interpersonal space, language, religion and Universalists (rules) particularisms'/ relationships.) is an important first step. Beyond that, the cross cultural conflict can be moderated by using international consultants and building cross cultural relationships.

\subsection{Dysfunctional conflict management styles}

People tend to handle negative conflict in patterned ways referred to as styles. Several conflict styles have been categorized over the years. According to conflict specialist Afzalur Rahim's model, five different conflicthandling styles are identified. There is no single best style; each has strengths and limitations and is subject to situational constraint.

Integrating:- in this style interested parties confronted the issue and cooperatively identify the problem, generate and weigh alternative solutions, and select a solution. Integrating is appropriate for complex issues plagued by misunderstanding. However, it is inappropriate for resolving conflicts rooted in opposing value systems. Its primary strength is its longer lasting impact because it deals with the underlying problem rather than merely with symptoms. The primary weakness of this style is that it is very time consuming.

Obliging (smoothing):- an obliging person neglects his or her own concern to satisfy the concern of the other party. This style, often called smoothing, involves playing down differences while emphasizing communalities. Obliging may be an appropriate conflict handling strategy when it is possible to eventually get something in return. But it is inappropriate for complex or worsening problems. Its primary strength is that it encourages cooperation. Its main weakness is that it's temporary fix that fails to confront the underlying problem. Dominating (forcing):- high concern for self and low concern for others encourages "I win you lose" tactics. The other party's need is largely ignored. This style is often called forcing because it relies on formal authority to force compliance. Dominating is appropriate when an unpopular solution must be implemented, the issue is minor or a deadline is near. It is appropriate in an open and participative climate. Speed is its primary strength. Primary weakness of this domineering style is that it often breeds resentment.

Avoiding: This tactic may involve either passive withdrawal from the problem or active suppression of the issue. Avoidance is appropriate for trivial issues or when the costs of confrontation outweigh the benefits of resolving the conflict. It is inappropriate for difficult and worsening problems. The main strength of this style is that it buys time in unfolding or ambiguous situations. The primary weakness is that the tactic provides a temporary fix that sidesteps the underlying problem.

Compromising:- This is a give-and-take approach involving moderate concern for both self and others. Compromise is appropriate when parties have opposite goals or possess equal power. But compromise is inappropriate when overuse would lead to inconclusive action (e.g., failure to meet production deadlines). The primary strength of this tactic is that the democratic process has no losers, but it's a temporary fix that can stifle creative problem solving [12].

\subsection{Choosing the best conflict management style}

The collaborative style is usually recognized as the preferred approach to conflict resolution. For example, the collaborative conflict management style results in better joint venture performance. The parties discuss concerns more quickly and openly, seek their partners opinions, and explain their course of action more fully than when a non-collaborative style is used. However, this style works only under certain conditions.

Specifically, it is best when the parties do not have perfectly opposing interests and when they have enough trust and openness to share information. Collaborating is usually desirable because organizational conflicts are rarely won-loss situations. There is usually some opportunity for mutual gain if the parties search for creative solutions.

You might think that avoiding is an ineffective conflict management strategy, but it may be the best approach when the issue is trivial or as a temporary tactic to cool down heated disputes. However, conflict avoidance should not be a long-term solution because it increases the other party's frustration.

The competing style of conflict resolution is usually inappropriate because organizational relationships rarely involve complete opposition. However, competing may be necessary when you know you are correct and the dispute requires a quick solution. For example, you might use the competing style when you believe the other party's position is unethical or when it otherwise violates your fundamental values. The competing style may also be necessary when the other party would take advantage of more cooperative strategies.

The accommodating style may be appropriate when the other party has substantially more power or the 
issue is not as important to you as to the other party. On the other hand, Clarify rules and procedures accommodating behaviors may give the other side unrealistically high expectations,

There by motivating that party to seek more from you in the future. In the long run, accommodating may produce more conflict rather than resolve it.

The compromising style may be best when there is little hope for mutual gain through problem solving, both parties have equal power, and both are under time pressure to settle their differences. However, compromise is rarely a final solution and may cause the parties to overlook options for mutual gain.

\section{7 Third-Party Interventions}

Many disputes in organizational settings are also resolved with the assistance of a third party. Third-party conflict resolution is any attempt by a relatively neutral person to help parties resolve their differences-ranging from formal labor arbitration to informal managerial interventions to resolve disagreements among employees. [15].

There are four main objectives in third-party conflict resolution. One objective is efficiency. Those who take the third-party role try to resolve the dispute quickly and with minimum expenditure of organizational resources. Second, conflict resolutions should be effective, meaning that the process should find the best longterm solution that will correct the underlying causes of the conflict. Third, this process should have outcome fairness. This objective ensures that the parties feel the solution provided by the third party intervention if fair. Although outcome fairness is similar to effectiveness, they are not the same, because people sometimes think that a solution is fair even though it does not work well in the long term.

Finally, third-party conflict resolution should ensure that the parities feel the dispute resolution process is fair, whether or not the outcome is favorable to them. This objective, known as procedural fairness, is particularly important when the third party makes a binding decision to resolve the dispute. In such situations, procedural fairness increases when the third party isn't biased (e.g., doesn't have vested interest toward one party), is well informed about the facts of the situation, and has listened to all sides of the dispute. It also increases when the decision can be appealed to a higher authority and the third party applies existing policies consistently [16]. There are two major third parties conflict resolution method, these are:

A. Conflict triangles:-occurs when two peoples are having a problem and instead of addressing the problem directly with each other, one of them gets a third person involved.

B. Alternative Dispute Resolution (ADR):- Disputes between employees, between employees and their employer, and between companies too often end up in lengthy and costly court battles. A more constructive, less expensive approach called alternative dispute resolution has enjoyed enthusiastic growth in recent years. In fact, the widely imitated people's Court-type television shows operating outside the formal judicial system are part of this trend toward what called calls "do-it-yourself justice." Alternative dispute resolution (ADR) uses faster, more userfriendly methods of dispute resolution, instead of traditional, adversarial approaches (such as unilateral decision making or litigation). The following ADR techniques represent a progression of steps third parties can take to resolve organizational conflicts. They are ranked from easiest and least expensive to most difficult and costly. A growing number of organizations have formal ADR policies involving an established sequence of various combinations of these techniques:

- Facilitation:- A third party, usually a manager, informally urges disputing parties to deal directly with each other in a positive and constructive manner. This can be a form of detangling, as discussed earlier.

- Conciliation:- A neutral third party informally acts as a communication conduit between disputing parties. This is appropriate when conflicting parties refuse to meet face to face. The immediate goal is to establish direct communication, with the broader aim of finding common ground and a constructive solution.

- Peer review: - A panel of trustworthy co-workers, selected for their ability to remain objective, hears both sides of a dispute in an informal and confidential meeting. Any decision by the review panel may or may not be binding, depending on the company's ADR policy. Membership on the peer review panel often is rotated among employees.

- Ombudsman:- Someone who works for the organization, and is widely respected and trusted by his or her coworkers, hears grievances on a confidential basis and attempts to arrange a solution. This approach permits someone to get help from above without relying on the formal hierarchy chain.

- Mediation:- "The mediator-a trained, third-party neutral-actively guides the disputing parties in exploring innovative solutions to the conflict. Although some companies have in-house mediators who have received ADR training, most also use external mediators who have no ties to the company. Unlike an arbitrator, a mediator does not render a decision. It is up to the disputants to reach mutually acceptable decision.

Arbitration:-disputing parties agreed ahead of time to accept the decision of a neutral arbitrator in a formal art like setting, often complete with evidence and witness. Participation in this form of ADR is voluntary, and statements are confidential Decisions are based on legal merits [17]. 


\section{Data Analysis and Discussion}

\subsection{Introduction}

As it was already mentioned in the research methodology part, questionnaire is used as primary data collection method. It is distributed to the respondents by categorizing them in to two. The first type of the questionnaire is distributed to Administrative staff and the second type of questionnaire is distributed to Academic staff and respondents who are neither academic staff nor administrative staff, (which we call them "Nonacademic staff" now onwards for sake of consistency). Out of 35 questionnaires distributed to Administrative staff of the organization, only 31 of them are returned back and out of 65 questionnaires distributed to Academic and nonacademic staff, only 60 of them was retuned back. So In this chapter the information gathered from the respondents' is analyzed.

\subsection{Existence of conflict and perception on conflict}

As it is already said in the introductory part and literature review part of this paper now a days, conflict becomes an inevitable aspect of organizations. So it is un doubtful for every organization and almost every individual in an organization to get involved in conflict with people around him/her. With this regard, the respondents are asked as to whether they have ever encountered conflict with people in their work place. Accordingly, $18(58 \%)$ of them respond as they encountered conflict with people with which they worked. The rest $13(42 \%)$ of the respondents respond as if they are not ever get in to conflict with people. This figure shows that most of the Administrative staff in an organization are get in to conflict with one or another party.

The next question solicited was the frequency in which they get into conflict with people in their work place accordingly out of 18 respondents who responded as they get in to conflict with people in work place $3(16 \%)$ of them replied very often, $4(6 \%)$ of the respondents said often and the rest $9(50 \%)$ of them said respond as the conflict arises rarely. From this data we can conclude that most of the respondents get in to conflict with people in their work place rarely. But this does not mean that they are free of conflict. It is solely a comparative explanation for existence and frequency of conflict.

3.2.5 Sources of conflict

The sources of conflict in an organization are broadly classified in to three. The first one is personal factors which include emotions of the individual, values and ethics of the person, attitudes and perceptions, skills and responsibility diversity of the person jealousy and the like. To this end, all of the respondents (31 or $100 \%$ of them) replied that all of those factors are the personal sources of conflict in the organization.

The second group of source of conflict in an organization is structural factors. The typical factors under this are Goal differences, status inconsistencies, scarcity of resources, interdependence, unclear job boundary and relationship among authorities. To this end, all of the respondents replied again as if all of these structural factors mentioned above are source of conflict in an organization. Specially, interdependence (relationship between several works and work units) in an organization and unclear job boundary (absence of demarcation between the responsibility that each parties in an organization are supposed to assume) are the two most prominent sources for most of the conflicts happen in the organization.

The third source of conflict in Madda Walabu University is a communication factors. The major communication factors brings conflict in an organization includes: distorted message (a message which missed its original nature and content because of length of communication channel and parties involved in the channel), Information overload (sending a lot of information at once which creates difficulty to grasp and catch all the sent message), Emotional state, lack of communications kill, use of Jargon (technical words which are only related to some fields), information late delivery, error in perception and empathy (recognizing all individuals to be communicated as if he have equal understanding ability with the sender and the rest of receivers). With this regard also, all of the solicited respondents replied as if all of these communication factors are the sources conflict in the organization.

In addition to the aforementioned three major sources of conflict, several other factors can also cited as sources of conflict in an organization. These are: penalties, policies and procedures, reward system, cultural differences, less obedience, performance appraisal system and result and assignment of task. All of these factors are recognized by $31(100 \%)$ of the respondents as a possible sources of conflict in an organization. Specially, penalties, reward system and problems on policies and procedures are the upper most three reasons that are resulting in conflict in the organization.

3.2.6 Conflict out comes

The outcomes of any conflict can be functional or dysfunctional. A given conflict outcome is functional if it results in some useful or beneficial outcomes for the organization. The conflict is dysfunctional if it brings some harmful out comes which may hampers the overall organizational efficiency and effectiveness. To this end, the respondents are solicited about the outcomes of conflicts that are encountered by the organization accordingly, $6(19 \%)$ of them said that the conflict's outcome was functional, 11(35\%) of them replied as it was dysfunctional and the rest $14(46 \%)$ respond as if it resulted in both functional and dysfunctional out comes. 
The next question asked the respondents about the possible functional outcomes of the conflict. Actually, there are large number of functional out comes of conflict. The typical ones are promotion of organizational vitality, motivation of change, increased commitment, and it can leads to new ideas and innovation. Accordingly, all (31 or $100 \%)$ of the respondents replied as all of these can be cited as a functional outcomes of conflict in the organization. The other question requested the respondents to identify dysfunctional out comes of conflict. Basically, the dysfunctional outcomes of conflict incorporate Employee turnover, customer dissatisfaction, distorted group cooperation, increased job dissatisfaction, resource wastage, diversion of energy form work, creation of negative climate and it also results in inefficiency. Accordingly $31(100 \%)$ of the respondents replied as if all of these can be taken as potential dysfunctional conflict out comes in an organization. specially, employee turnover and an increased job dissatisfaction becomes the major head ache of the organization.

3.2.7 Conflict management styles.

Majority of organizational behaviorists and psychologists recognized the fact that conflict management is a difficult task to perform. Actually this reality pertains to several reasons like difference in personality, cultural differences between parties involved in conflict, lack of conflict management skill, difference in status between all the parties. Accordingly, the respondents are asked about whether they think as if conflict management is difficult task or not. Accordingly all of the respondents replied that it is difficult task because of all the reasons mentioned above. The proceeding question requested the respondents to identify the best conflict management style for them out of the alternatives provided. Accordingly, 5(16\%) of them replied that Avoiding (ignoring) is best, $7(23 \%)$ selected negotiation, $7(23 \%)$ selected integration (coordination) $5(16 \%)$ selects compromising, $3(10 \%)$ third party intervention and the rest $4(12 \%)$ selected obliging (smoothing).

3.2.8 Conflict management practice of the organization

The respondents are asked about the conflict management practice of the organization. Accordingly, 3(10\%) of them replied it is excellent $3(10 \%)$ of them said it is very good,4(13\%) of them respond it is fair and the rest $21(67 \%)$ of them said it is poor .From this we can say that majority of the respondents feel as the management practice of the organization is poor.

3.2.9 Training on conflict management

In order to equip their workers with the required necessary skill, it is a must for every organization to prepare special training programs. Specifically organizations are required to provide special training for their worker on areas of conflict management to enable an individuals to develop a skill of managing conflicts arise in an organization between several partied and to enable them to grasp the essence of conflict appropriately. With this regard, the respondents were asked whether they ever got any chance to participate on a training which is prepared on area of conflict management, accordingly $5(16 \%)$ of them replied as they get the chance to participate and the rest $26(84 \%)$ of them replied as they didn't get a chance to participate on such trainings. From this data we can easily observe that the organization is poor at coordinating and preparing trainings on conflict management areas, even though the area is too sensitive and necessary. The next question solicits those individuals who got the chance to participate on training prepared on areas of conflict management about how they find the training. Accordingly 4 of them said it is poor and 1 of them said it is good. So this again brings us to the conclusion that the trainings ever given also lack quality. The last question the respondents requested in this part is whether or not they applied what they learnt on training. Accordingly 5 of them (all of them) replied they did not apply it.

3.2.10 Effect of Gender on conflict management

Several individual perceives that gender have an effect on conflict management effectiveness. To this end, the respondents are asked whether they think as if gender has an impact on effectiveness on conflict management or not. Accordingly, 11 (48\%) of them said as gender have an impact on conflict management effectiveness. The rest $12(52 \%)$ of them respond as gender have no impact on conflict management. The last question asked the respondents about which gender they thank in effective in managing conflict. Accordingly $7(22 \%)$ of them said male, $8(26 \%)$ of them said female and the rest $16(52 \%)$ respond as it depends on situations.

3.3.1 General Bio data of respondents

In this part a general bio data of the respondents from Academic and Non Academic staff members of the organization is collected. According to the information given by the respondent $33(55 \%)$ are male and $27(45 \%)$ of them are female. Regarding the age distribution of the respondents, 18(30\%) of the respondents lies between $21-25,30(50 \%)$ of them are aged between $26-30,6(10 \%)$ of them are between $31-40$ and the rest $6(10 \%)$ are aged above 40. From this fact we can say that most of the Academic and non- academic staff of the organization are youngsters aged between 25-30 years. As previously said, this age is an age in which peoples are more reactive to conflict. So this can contribute a lot towards determining the level of conflict in an organization.

Regarding the respondents educational status, $2(3 \%)$ of them are grade 12 complete, $6(10 \%)$ of them are certificate holders, $16(27 \%)$ of them are diploma holders, $20(33 \%)$ of the respondent are BA (BSC) holders, 14 $(24 \%)$ of the respondent are MA (MSC) holders and the rest $2(3 \%)$ of the respondents are PhD holders. From this information, we can easily observe the fact that most of the workers in an organization have good 
educational status. With respect to the marital status of the respondents, $42(70 \%)$ of them are single and only $18(30 \%)$ of the respondents are married.

The next question provided for the respondents is the number of years of experience that the accumulated in the organization. According to the information given above, $32(53 \%)$ of the respondents have 1-2 years of experience, $19(32 \%)$ of them have an experience of 3-4 years in the organization, $8(13 \%)$ of them have an experience of 5-6 years and the rest $1(2 \%)$ of the respondent has an experience of 8 years. This information shows that most of the academic and nonacademic staff members of the organization are new for the organization. As it is already known, new entrants to the organization are more exposed to conflict because of the fact that they may not get informed and well introduced and convinced with the organizational rules and procedures. Additionally this can also reflect that an organization is highly suffering from turn-over of its post employees.

3.3.3 Frequency of conflict and parties involved in it in the organization

Respondents are solicited an information regarding the frequency of conflict in the organization. Accordingly $7(12 \%)$ the respondents replied as it is very frequent, $23(38 \%)$ of them respond as it is frequent and the rest $30(50 \%)$ of the respondents answered that conflict is not frequent in the organization. Regarding the parties get in to conflict $8(13 \%)$ of the respondents respond as the conflict is between academic staffs of the organization, $20(33 \%)$ of the respondents respond as the conflict is exists between academic staff and students, $17(28 \%)$ of the respondent replied as the conflict is frequent between academic staff an administrative staff of the organization, $10(17 \%)$ of them said the conflict is observed often between administrative staff of the organization, the rest $5(9 \%)$ of the respondents replied that the conflict is also observed between academic staff and non academic staff of the organization.

3.3.4. The way academic and nonacademic staff members obtain information about an existence of conflict The respondents are asked about the way they get information about the existence of conflict. According to the information given above $28(47 \%)$ of the respondents respond as they get an information regarding existence of conflict through hearsay, $10(17 \%)$ of respondents replied that they get an information from friends and collageous, 9(15\%) respond as they get through formal report, 13(21\%) answered as they get an information from parties felt in conflict. From this information, we can conclude that most of the individuals get information about existence of conflict though informal way, which is more exposed to message distortion.

3.3.5 Conflict sources

As we said earlier, there are three major categories of sources of conflict these are personal factors, structural factors and communication factors. There are also additional sources of conflict out of the above three categories. Regarding the respondents reply, all of the respondents (60 or $100 \%$ of them) recognized all of the aforementioned sources of conflict as sources of conflict in an organization. Those sources of conflict are clearly defined in our previous part, i.e. analysis and presentation of data gathered from administrative staff members. So no detail explanation is given here to avoid redundancy.

3.3.6. Conflict out comes

In this part the respondents are solicited about an out comes of conflicts in the organization. Acordinglly $13(22 \%)$ of the respondents said it is functional, $17(28 \%)$ said the outcome is dysfunctional, 30(50\%) of them replied as the outcome is both functional and dysfunctional. Additionally, the respondents are requested to identify the possible types of functional and dysfunctional out comes of conflicts in the organization. Accordingly all of the respondents respond as all of what is listed down in the previous part are the possible functional and dysfunction out comes in the organization. Again the detail explanation is escaped to avoid redundancy.

3.3.7. Style of conflict management

All the respondents recognized the difficulty of conflict management because of the reasons stated in the previous part. Additionally, the respondents are requested about the conflict management style that they recognize as the best one. According to the information given by the respondent $8(3 \%)$ of the respondents replied as avoiding (ignoring) is the best style, 15(25\%) of them replied as Negotiation is the best, 15(25\%) replied as integrating (coordinating) is best, $8(13 \%)$ respond as compromising is the best style, $9(15 \%)$ respond as third party intervention is best and the rest $5(9 \%)$ respond as obliging (smoothing ) is the best style.

3.3.8 The institution's conflict management practice

The respondents are requested about the conflict management practice of the institution. Accordingly, 15(25\%) of them replied as it is good, 9(15\%) of the respondents replied as it is fair and the rest $34(60 \%)$ of the respondents replied as it is poor. This data shows that the organizations conflict management method is too problematic.

3.3.9 Training on issues related to conflict

The respondents are requested whether they are provided with training on issues related to conflict. Accordingly, all of the respondents replied as no training is given to them on the issue.. This information shows that the institution is really overlooking area. 


\subsubsection{Gender effect on conflict}

Respondents are asked whether gender have an effect on conflict management. Accordingly, 37(62\%) of them replied as gender can affect conflict management effectiveness and the rest 23(38\%) respond as it has no effect. Additionally, respondents are asked about which gender is better in managing conflict. Accordingly 19(32\%) of them replied as male are better, 18(30\%) replied as female are better and the rest $23(38 \%)$ replied as it depends on situations. This information shows as there is a great range of difference on perception regarding the gender effect on conflict management.

\section{Conclusions and Recommendations}

This paper is conducted under a title of "Conflict Management Practice "in Madda Walabu University. The information required for the study is collected by applying both primary and secondary data sources. 100 questionnaires are prepared and distributed to academic, nonacademic and administrative staff of the university college. The data gathered from these sources is analyzed and presented accordingly. Conclusions are drawn and recommendations are also forwarded based on what is concluded.

\section{Conclusions}

Based on the already analyzed data in the previous part, the following conclusions are drawn. Most of the institution's administrative staff members lies between the age of 25-40 where as most of the academic and nonacademic staff member's age is between 21-30.Large part the institution's staff members hold higher educational status.

* The years of experience of, most of the institution's staff members (of all types) ranges between 14.years

* At both individual and organizational level, most of the employees get in to conflict with several parties because of several reasons.

* Conflict is frequent between administrative and academic staff and between academic staff and students of the institution because of a wide range of conflict of interest.

* There is a great problem on perception of conflict i.e.; most of the individuals recognize all conflicts as harming the organization most of the individuals have not yet tried to induce conflict among individuals and most of the individuals relate absence of conflict in the organization with the organizational effectiveness.

* From conflict sources in the organization, work independence, unclear job boundaries, emotions, distorted messages, information's late delivery, penalties, reward system and policy and procedural problems are the major ones.

* Most of conflicts in the organization have dysfunctional outcomes.

* Increased rate of Turnover and job dissatisfaction are the two clearly and frequently observed dysfunctional conflict out comes in the organization.

* The organization has not ever prepared any special training program on conflict management related issues.

* The conflict management practice of the organization is too poor.

* There is a predisposition towards perceiving the impact of gender on conflict management effectiveness.

\section{Recommendations}

Based on the information concluded above, the following recommendations are forwarded:

$>$ The organization should use an advantage of having youngsters as academic staff members since they are in productive age but, great emphasis is required to be given on how to protect and manage conflicts happen between them since people in this age are more sensitive and reactive to conflict.

$>$ The institution should have to keep it up in hiring and retaining those highly educated professionals to increase its service quality, which in turn can boost the institution's reputation and good will.

$>$ The fact that most of the organization's staff members have few years of experience in the institution shows as there is great problem in retaining earlier staff. So the institution should have to develop several mechanisms that help to keep the employees with it.

$>$ The organization should create some special programs in which its employees develop a harmonies relationship among themselves. These programs are like special trips; get together, recreational tours ....etc.

$>$ The institution should also appreciate a social relationship among workers and the heads of the institution are supposed to play a figure head role by appearing on special occasions for the 
employees like, marriage, death... etc.

$>$ In order to minimize the frequent conflicts between the University academic and administrative staff and between the academic staff members and students of the institution, the following recommendations are helpful:The organization is required to put individuals who have the required skill of leading/directing in its administrative post.

$>$ Inducing functional conflicts is advantageous for the institution to be effective. So the institution's administrative officials are specially required to create such kinds of conflicts among workers to come up with increased productivity.

$>$ An absence of conflict in an organization cannot be an indicator for effectiveness of the organization necessarily. So the individuals in the organizations should stop to think as if the institution is effective because there is no conflict. Rather they are supposed to analyze the reason why the institution is dormant and take the necessary remedial action. There must be clearly set job boundary for all units and individuals operating in the organization in order to avoid a conflict results from presence of unclear job boundary.

$>$ There should be clear demarcation for those works which are performed interdependently and there should be rules and regulations for setting disputes which arise from work interdependence.

$>$ Managers in an organization should have to equip themselves with a mechanism to settle emotional expressions and feelings and an appropriate remedy should be taken accordingly

$>$ Every individual in an organization should refrain from transmitting distorted message and the organization should also set formal communication channel through which original information reaches each individual without distortion.

$>$ All the necessary information should be disseminated to the employees timely to avoid a conflict arise because of information's late delivery.

$>$ The organization should have to refrain itself from penalizing its employees as much as possible unless the problem created in Sevier. The procedures to penalize mistaken workers are also supposed to be communicated in advance to all of the workers in the organization.

$>$ The reward and promotion system of the organization requires great improvement. There should be clear cut procedures for promoting individuals in an organization. The reward provided is also supposed to have both internal and external equity.

$>$ The policies and procedures of the organization should have to be communicated to everybody as an orientation.

\section{References}

[1]. Callahan, Fleenor \& knodson, Understanding Organizational Behavior- Management View point, Charles. E. Merrill pub co. USA, 1986.

[2]. Dannis W. Organ and W. Clay Hammer,Organizartional Behavior, B business Publication Inc., USA,19989

[3]. David J. Cherrington, Organizational Behavior, Allyn and Bacon Inc., USA, 1989

[4]. Davis and Newton, Human Behavior At Work, Organizational behavior, McGraw-Hill, USA, 1990

[5]. Debra L.Nelson, James Cambell Quick, Organizational Behavior, West p.l.c., USA, 1997 .Fred Luthans, Organizational Behavior, McGraw-Hill, USA, 19993

[6]. Jits Chandan, Organizational Behavior, Vikas Pub. Co., India, Delhi, 1995 Judith R.Gordon, Organizational Behavior, 2nd edition, Allyn and Bacon Inc., USA, 1987

[7]. Randolph \& Blackburn, Managing Organizational Behavior, Richard D.Irwin, inc., USA, 1989

[8]Rashid \& Archer, Organizational Behavior, Methuen publication, Canada, 1963

[9]. Richard Rettinger, Organizational Behavior, Macmillan Press,, Great Britain,. 1996

[10]. Robert Kreitner and Angelo Kinicki, Organizational Behavior, 5th ed. McGraw Hill Higher Education, USA, 2001

[11]. Robert A. Baron \& Jerald Greenberg, Behavior in Organizations- Understanding \& Managing the Human side of work, 3rd Ed, Allyn \& Bacon, USA, 1990.Stephen Robbins, Organization Behavior, 7th Ed, prentice Hall Inc, USA, 1996

[12]. Steven L. Mcshane and Mary Ann Von Glinov, Organizational Behavior, 2nd edition, McGraw-Hill Higher Education, USA, 2003.

[13]. Stuart M. Klein and R. Richard Rihi, Understanding Organizational Behavior, Wadstwortrh Inc., USA, 1998 